\title{
Premenstrual Dysphoric Disorder and the Brain
}

\author{
C. NEILL EPPERSON, M.D. \\ Department of Psychiatry, Perelman School of Medicine at the University of Pennsylvania, \\ Philadelphia
}

In early December 2012, the APA Board of Trustees approved the fifth edition of the Diagnostic and Statistical Manual of Mental Disorders (DSM-5). With this vote, the board made history with respect to the classification of premenstrual disorders. By moving premenstrual dysphoric disorder (PMDD) from DSM-IV-TR Appendix B, "Criterion Sets and Axes Provided for Further Study," to a full diagnosis with a distinct diagnostic code under the category of mood disorders, the long-suspected biological and brain basis of this disorder has been emphasized. Since the time of Hippocrates (Figure 1), philosophers, physicians, and scientists have written about the links between menstruation, the brain, and behavior (1). However, recent decades have witnessed a backlash against the inclusion of PMDD and its previous diagnostic versions in the DSM. The argument is typically based on the concern that a formal diagnosis of premenstrual syndrome (PMS) or PMDD would pathologize the normal premenstrual physical and behavioral changes experienced by the majority of women or would suggest that all women are somehow compromised by the menstrual cycle.

The state that is required for the manifestation of PMDD symptoms, as well as certain disorder-specific brain differences, is the fluctuating hormonal milieu of the menstrual cycle.

Fortunately for the $2 \%-5 \%$ of women who suffer from this debilitating disorder, physicians who provide care for these women and scientists exploring the causes of PMDD have not been swayed by these arguments. Late luteal phase dysphoric disorder (LLPDD) was included in Appendix A of DSM-III-R in 1987 (2), and research continues to codify the type of symptoms experienced by the most affected women, to confirm their temporal association with menstrual cycle phases and related hormonal changes, and to study the efficacy or lack thereof of various pharmacological and hormonal treatment strategies $(3,4)$. With this said, the application of modern scientific techniques to the study of premenstrual disorders over the past 40 years has lagged behind the study of brain disorders in general. Peripheral markers of CNS dysfunction were examined in schizophrenia in the early 1970s, but not until 1987 did Rapkin et al. (5) report abnormalities in whole blood serotonin in PMS. Likewise, the first psychophysiological techniques were applied to the study of schizophrenia in the early 1970s and to anxiety disorders soon thereafter. No publications described the results from an acoustic startle study in women with PMDD until 2007, when menstrual cycle phase-by-diagnosis differences in baseline arousal were observed (6). 
Magnetic resonance (MR) techniques were first used in the study of psychiatric disorders, in this case schizophrenia, in the early 1980s, but the application of brain imaging techniques for PMS and PMDD would not occur for another two decades $(7,8)$. If one assumes that the advent of modern research in the pathophysiology of premenstrual disorders is temporally linked to the inclusion of LLPDD in the appendix of DSM-III-R in 1987, it may be safe to say that the inclusion of PMDD as a full diagnosis in DSM-5 will further galvanize the study of this important disorder.

Referable to this latter point is the article by Baller et al. (9) in this issue of the Journal. This elegant study uses the same scientific method-namely, hormone add-back after treatment with gonadotropin-releasing hormone agonist $(\mathrm{GnRH})$ - that provided some of the first confirmation that normal levels of estradiol and progesterone trigger negative affect in women with premenstrual dysphoria but not in healthy women (10). That women with PMDD are "sensitive" to the normal hormonal perturbations of the menstrual cycle, particularly those occurring after ovulation, has been suspected but not established by previous research. In the Baller et al. study, the GnRH hormone add-back paradigm was combined with functional MRI (fMRI) and positron emission tomography (PET) to examine the impact of hypogonadism (GnRH condition) and physiological levels of estrogen and progesterone individually on cerebral blood flow and brain activation in the functionally relevant areas of the prefrontal cortex. To probe for functional activity in the brain regions responsible for executive functions, including working memory and affect processing and regulation, the authors used the n-back task, which robustly activates dorsolateral prefrontal cortex neural circuitry, a potent target for ovarian hormones.

The women in the study underwent rigorous screening to confirm the presence or absence of PMDD using prospective daily ratings of mood and physical symptoms as first recommended in DSM-III-R for the diagnosis of LLPDD. With accepted cutoffs for symptom severity and impact on function, the women enrolled in the PMDD patient group experienced some degree of functional impairment from their illness. A strength of the study design is the number of women who underwent both fMRI and PET imaging: 11 with PMDD and seven without. Findings from this multimodal imaging study converge to implicate dysregulation in the working memory neural circuitry, specifically in the dorsolateral prefrontal cortex and medial frontal gyrus, in women with PMDD. Brain activation was greater in these regions in women with PMDD relative to comparison subjects, regardless of hormonal condition. As detected in a study by Rapkin et al. (11), Baller and colleagues also observed heightened cerebellar activation in women with PMDD relative to comparison subjects, although in the former study the degree of activation was affected by menstrual cycle phase.

The relevance of the prefrontal cortex regions to the pathogenesis of PMDD is highlighted by the inverse correlation between Global Assessment of Functioning Scale scores and activation observed with both brain imaging modalities, indicating that more severely affected women display the greatest activation in brain regions where women with PMDD differ most from healthy comparison subjects. Age at illness onset was inversely correlated with activation in the dorsolateral prefrontal cortex, while the overall severity of baseline symptoms and the severity of irritability were both correlated with bilateral activation in the 
dorsolateral prefrontal cortex. Interestingly, irritability is the second most frequently reported symptom of PMDD (mood lability being the first), and it is the symptom most commonly associated with PMS and PMDD among the general population $(3,12)$. Again, these correlations between markers of severity and the degree and location of brain activation were observed in all three hormonal conditions, when negative affect was not present (GnRH agonist treatment alone) and when negative affect was present (estrogen and progesterone add-back phases). These enduring differences between women with PMDD and healthy comparison subjects regardless of hormonal status have been observed in several studies of naturally cycling women and suggest an overarching trait vulnerability to the disorder. In contrast, a number of research paradigms have revealed menstrual cycle-bydiagnosis interactions, with biological differences between women with PMDD and healthy comparison subjects observed only in the follicular or luteal phases of the menstrual cycle. These findings include diagnosis-by-menstrual cycle phase differences in neuro-transmitter level (8), motor cortex inhibition (13), brain activation $(14,15)$, and psychophysiology (6), to name a few.

Abnormalities in stress neurocircuitry and prefrontal, top-down control over subcortical structures are certainly not specific to women with PMDD, which is a factor that could be used to argue against the distinctive nature of the disorder. However, unlike major depression, bipolar disorder, or any anxiety disorder, the state that is required for the manifestation of PMDD symptoms, as well as certain disorder-specific brain differences, is the fluctuating hormonal milieu of the menstrual cycle.

In summary, the brain origin of premenstrual mood disturbances has been recognized in some fashion since antiquity, and the burden of the disease is well established (16). The Baller et al. study provides additional evidence, using the most modern scientific methodologies readily available, that brain structure and function are altered in women with PMDD. In the coming years, the challenge will be to further refine our understanding of trait vulnerabilities and aspects of the hormonal state that are necessary and sufficient to manifest the symptoms of PMDD in order to better inform treatment and improve the quality of life for this sizable minority of women.

\section{Acknowledgments}

Dr. Epperson receives research or product support from Shire and Novartis. Dr. Freedman has reviewed this editorial and found no evidence of influence from these relationships.

\section{References}

1. O'Brien, PMS.; Ismail, KMK. History of premenstrual disorders. In: O’Brien, PMS.; Rapkin, AJ.; Schmidt, PJ., editors. The Premenstrual Syndromes: PMS and PMDD. London: Informa Healthcare; 2007.

2. Spitzer RL, Severino SK, Williams JB, Parry BL. Late luteal phase dysphoric disorder and DSMIII-R. Am J Psychiatry. 1989; 146:892-897. [PubMed: 2742015]

3. Epperson CN, Steiner M, Hartlage SA, Eriksson E, Schmidt PJ, Jones I, Yonkers KA. Premenstrual dysphoric disorder: evidence for a new category for DSM-5. Am J Psychiatry. 2012; 169:465-475. [PubMed: 22764360] 
4. Freeman EW, Rickels K, Sondheimer SJ, Polansky M. Differential response to antidepressants in women with premenstrual syndrome/premenstrual dysphoric disorder: a randomized controlled trial. Arch Gen Psychiatry. 1999; 56:932-939. [PubMed: 10530636]

5. Rapkin AJ, Edelmuth E, Chang LC, Reading AE, McGuire MT, Su TP. Whole-blood serotonin in premenstrual syndrome. Obstet Gynecol. 1987; 70:533-537. [PubMed: 3627623]

6. Epperson CN, Pittman B, Czarkowski KA, Stiklus S, Krystal JH, Grillon C. Luteal-phase accentuation of acoustic startle response in women with premenstrual dysphoric disorder. Neuropsychopharmacology. 2007; 32:2190-2198. [PubMed: 17314917]

7. Rasgon NL, Thomas MA, Guze BH, Fairbanks LA, Yue K, Curran JG, Rapkin AJ. Menstrual cyclerelated brain metabolite changes using $1 \mathrm{H}$ magnetic resonance spectroscopy in premenopausal women: a pilot study. Psychiatry Res. 2001; 106:47-57. [PubMed: 11231099]

8. Epperson CN, Haga K, Mason GF, Sellers E, Gueorguieva R, Zhang W, Weiss E, Rothman DL, Krystal JH. Cortical gamma-aminobutyric acid levels across the menstrual cycle in healthy women and those with premenstrual dysphoric disorder: a proton magnetic resonance spectroscopy study. Arch Gen Psychiatry. 2002; 59:851-858. [PubMed: 12215085]

9. Baller EB, Wei S-M, Kohn PD, Rubinow DR, Alarcón G, Schmidt PJ, Berman KF. Abnormalities of dorsolateral prefrontal function in women with premenstrual dysphoric disorder: a multimodal neuroimaging study. Am J Psychiatry. 2013; 170:305-314. [PubMed: 23361612]

10. Schmidt PJ, Nieman LK, Danaceau MA, Adams LF, Rubinow DR. Differential behavioral effects of gonadal steroids in women with and in those without premenstrual syndrome. N Engl J Med. 1998; 338:209-216. [PubMed: 9435325]

11. Rapkin AJ, Berman SM, Mandelkern MA, Silverman DH, Morgan M, London ED. Neuroimaging evidence of cerebellar involvement in premenstrual dysphoric disorder. Biol Psychiatry. 2011; 69:374-380. [PubMed: 21092938]

12. Hartlage SA, Freels S, Gotman N, Yonkers K. Criteria for premenstrual dysphoric disorder: secondary analyses of relevant data sets. Arch Gen Psychiatry. 2012; 69:300-305. [PubMed: 22393222]

13. Smith MJ, Adams LF, Schmidt PJ, Rubinow DR, Wassermann EM. Abnormal luteal phase excitability of the motor cortex in women with premenstrual syndrome. Biol Psychiatry. 2003; 54:757-762. [PubMed: 14512217]

14. Bannbers E, Gingnell M, Engman J, Morell A, Comasco E, Kask K, Garavan H, Wikström J. Sundström Poromaa I: The effect of premenstrual dysphoric disorder and menstrual cycle phase on brain activity during response inhibition. J Affect Disord. 2012; 142:347-350. [PubMed: 22840469]

15. Protopopescu X, Tuescher O, Pan H, Epstein J, Root J, Chang L, Altemus M, Polanecsky M, McEwen B, Stern E, Silbersweig D. Toward a functional neuroanatomy of premenstrual dysphoric disorder. J Affect Disord. 2008; 108:87-94. [PubMed: 18031826]

16. Halbreich U, Borenstein J, Pearlstein T, Kahn LS. The prevalence, impairment, impact, and burden of pre-menstrual dysphoric disorder (PMS/PMDD). Psychoneuroendocrinology. 2003; 28(suppl 3):1-23. 


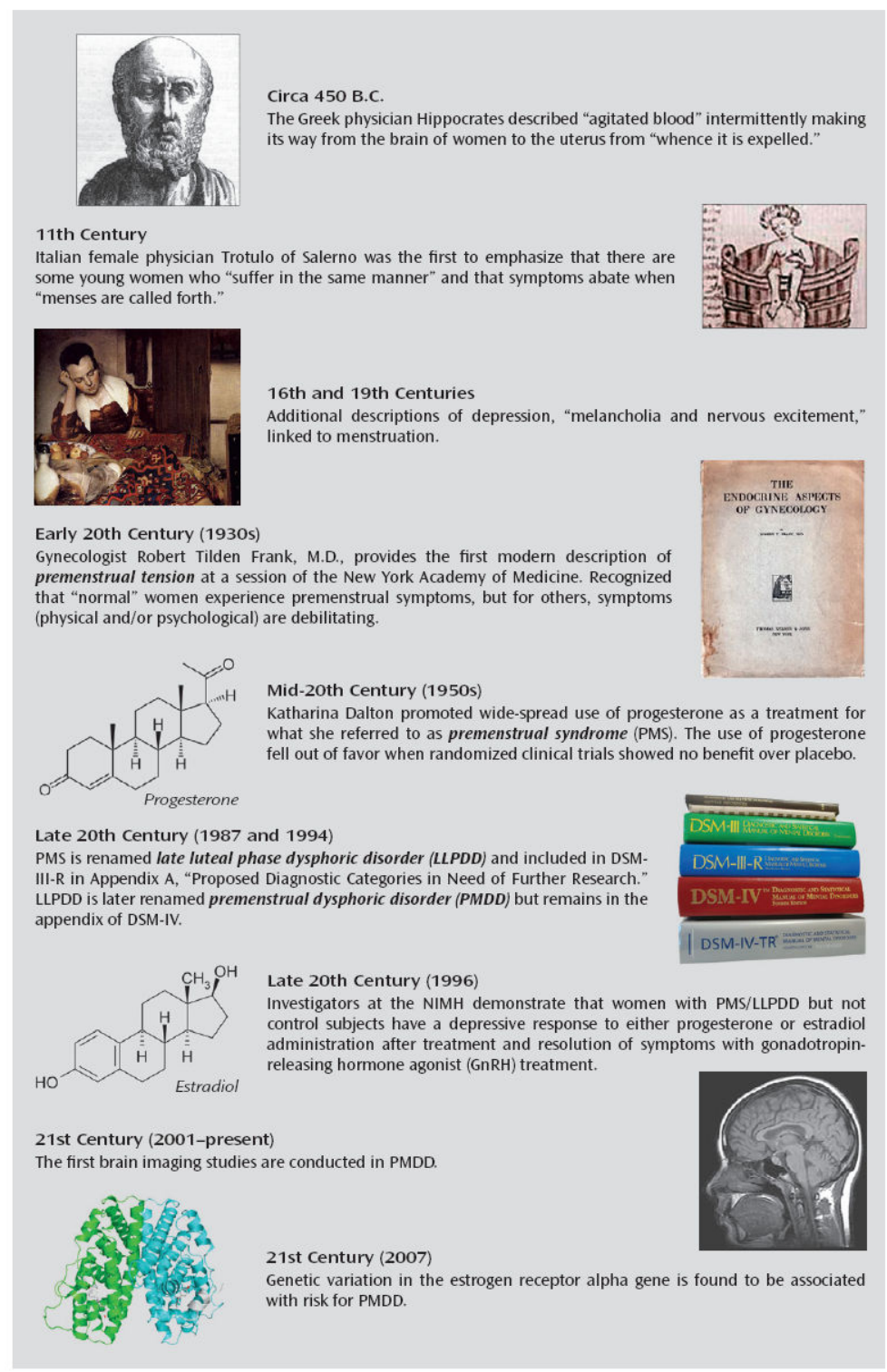

FIGURE 1.

A Brief Overview of Discourse Regarding Premenstrual Mood and Physical Disturbances From Antiquity to Modern Day ${ }^{\mathrm{a}}$

aThis summary timeline, drawn in part from O'Brien and Ismail (1), is not meant to be exhaustive. Instead, it highlights the common thread between early observers and modernday physicians and scientists with respect to beliefs and scientific evidence regarding the link between the brain, behavior, and menstruation. 